\title{
Sorani Kurdish and Minimalism *
}

Hiba Esmail Gharib, PhD in Language and Linguistics,University of Sulaimiani-Iraq

\begin{abstract}
Sorani is a dialect of Kurdish that is spoken in many countries of the world. In Sorani there is an agreement marker that appears on the verb and makes the verb agrees with the subject in person and number. A close examination of the nature of the agreement marker in Sorani shows that it is not obvious whether it is a suffix or a clitic. In this research I will discuss the properties of the affixes and clitics in general, and then apply them to the data in Sorani to decide whether the agreement marker is an affix or a clitic. The agreement marker in Sorani in the past tense verbs requires reconsideration as in the past tense; the agreement marker appears on the object instead of the verb. Subject agreement in Sorani is considered a challenge to the syntactic theories as there is no good explanation available to understand this phenomenon. In my research will explore the nature of this agreement marker as this would be the key to explaining the agreement phenomenon in Sorani.
\end{abstract}

\section{Introduction}

Sorani or as many other linguist prefer to call it Central Kurdish is one dialect of the Kurdish language spoken in northern Iraq and the north- west of Iran. Kurdish is a member of the IndoEuropean language family (Abdulla, 1976; Bodnarchuk, 2000). The current work examines subjectverb agreement in Sorani. The agreement system in this dialect is interesting as the agreement marker appears on intransitive verbs in all tenses and the transitive verbs in the present tense, while it appears on the object with the transitive verb in the past tense.

Kurdish is an SOV language as illustrated in the examples below:

(1) Kur- aka dar- aka da- shke- ne- e boy- the- wood- the asp- break.pres cause $3 \mathrm{~s}$

"The boy breaks the wood"

(2) To nan- aka- $t$ xward you bread- the- 2 s eat.pas

"You ate the food"

The above word order is the canonical word order in the declarative sentences; in all the above sentences the subject comes initially followed by the object and then the verb. Any change in the word order would either produce an ungrammatical sentence or change the sentence from declarative to exclamative.

\section{Agreement in Sorani}

There are two types of agreement features in Sorani: number and person. The most straightforward type of agreement is shown in sentences involving nominals with overtly marked singularity or plurality and agreeing with verbs and pronouns:

(3) - pe- e- gut

(he) to- $1 \mathrm{~s}$ tell.pas

"He told him"

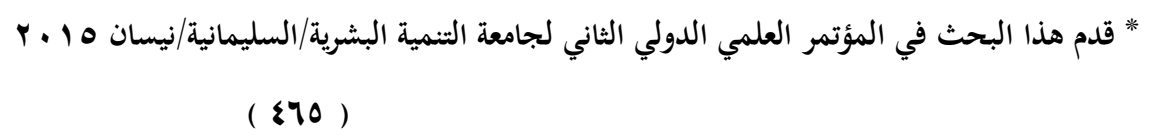


(4) - pe- y- an- gut

(they) to- 3s- pl- tell.pas

"They told him"

The distinction between $-e$ in (3) and -yan in (4) corresponds to the overtly marked singularplural distinction between kur "boy" and kuran "boys."

There is agreement between the verb and the subject as the following sentences show:

(5) Min dar- aka da- shke- ni- m

I wood- the asp- break.pres cause $1 \mathrm{~s}$

"I break the wood"

(6) To dar- aka da- shke- ni- t

you wood- the asp- break.pres- cause $2 \mathrm{~s}$

"You break the wood"

(7)

aw dar- aka da- shke- ni- i

s/he wood- the asp- break.pres- cause $3 \mathrm{~s}$

"S/he breaks the wood"

(8) ema dar- aka da- shke- ni- $n$

we wood- the asp- break.pres- cause- 1s.pl

"We break the wood"

(9)

\begin{tabular}{|c|c|c|c|}
\hline $\begin{array}{l}\text { ewa dar- aka da- } \\
\text { You pl wood- the } \\
\text { "You break the wood" }\end{array}$ & $\begin{array}{l}\text { shke- } \\
\text { break.pres- }\end{array}$ & $\begin{array}{c}\text { ni- } \\
\text { cause- }\end{array}$ & $\begin{array}{l}\mathbf{n} \\
2 \mathrm{~s} . \mathrm{pl}\end{array}$ \\
\hline $\begin{array}{l}\text { awan dar- aka da- } \\
\text { they wood- the asp- } \\
\text { "They break the wood" }\end{array}$ & $\begin{array}{l}\text { shke- } \\
\text { break.pres- }\end{array}$ & $\begin{array}{l}\text { ni- } \\
\text { cause- }\end{array}$ & $\begin{array}{l}\text { n } \\
3 \mathrm{~s} . \mathrm{pl}\end{array}$ \\
\hline
\end{tabular}

As sentences 5, 6, and 7 show, the verb is in total agreement with subject. In (5), the subject is represented by $\min$ ' $\mathrm{I}$ ' and the agreement marker that appears on the verb is $-m$ which matches the subject as a first person singular. In (6) the subject is second person singular which is represented by to 'you' and the agreement marker - $t$ that appears on the verb matches and agrees with the subject in person and number. Sentences 5, 6, 7, 8, 9, 10,11, and 12 all include transitive verbs in the present tense and the agreement marker appears at the end of the verb. The agreement marker also appears on the intransitive verb whether the verb is in the past as in 11,12,14,15, and 16, or in present tense as in 13:

$$
\begin{aligned}
& \text { min rwishti- } \mathbf{m} \text { bo qutabxana } \\
& \text { I go.pas- 1s to school } \\
& \text { "I went to school" }
\end{aligned}
$$

(12) To rwsht- eet bo qutabxana you go.pas- $2 \mathrm{~s}$ to school "You went to school"

(13) Aw da- rwa- $\mathbf{t}$ bo qutabxana 
s/he asp- go.pres. $3 \mathrm{~s}$ to school

"She goes to school"

(14)

ema rwisht- een bo qutabxana
we go.pas- 1s.pl to school
"We went to school"

ewa rwish- $t-$ in bo qutabxana

you pl go.pas- 3s- pl to school "you went to school"

(16)

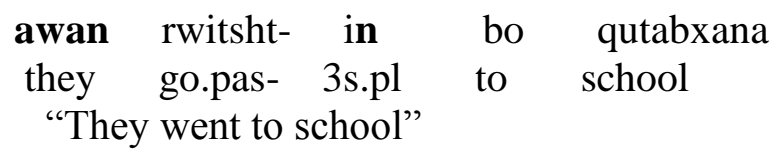

Things seem smooth and clear, Sorani is a dialect in which there is an agreement marker that appears on the verb and makes the verb agrees with the subject in person and number. But past tense verbs require reconsideration. In the past tense, the agreement marker appears on the object instead of the verb:

Min dar- aka- $\mathbf{m}$ shka-
I wood- the-
"I broke the wood"

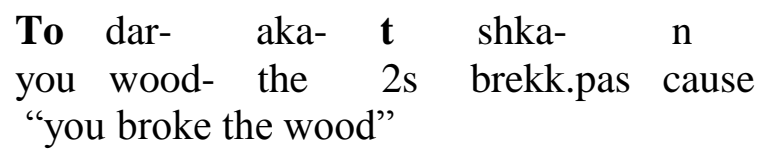

$$
\begin{aligned}
& \text { aw dar- aka- i shka- n } \\
& \text { s/he wood- the- } 3 \mathrm{~s} \text { break.pas cause } \\
& \text { "S/he broke the wood" }
\end{aligned}
$$

(20) ema dar- aka- m- an shka-

nd

we wood -the 1s. pl break.pas-cause

"We broke the wood"

(21) ewa dar- aka- t- an shka- $\mathrm{n}$

You pl wood- the- 2s pl break.pas cause

"You broke the wood"

awan dar- aka- yan
they wood- the- 3s-pl
"They broke the wood"


As it is shown above, the agreement marker appears on the object dara-ka 'the wood' instead of the verb shka 'break,' and cannot appear on the verb as it will result in ungrammatical sentences as exemplified in the sentences below:

$\begin{array}{lllc}\text { * Min dar- aka- } & \text { shka- } & \text { n- } & \text { m } \\ \text { I wood- the } & \text { break.pas } & \text { cause } & 1 \mathrm{~s} \\ \text { "I broke the wood" } & & & \end{array}$

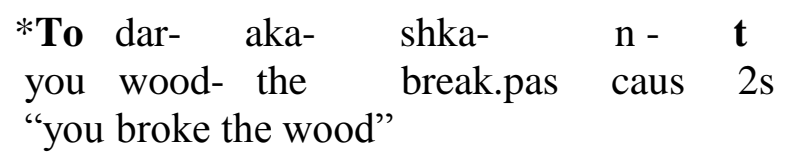

*aw dar- ak- shka- n- i s/he wood- the break.pas caus $3 \mathrm{~s}$

"S/he broke the wood"

*ema dar- aka- shka-
we wood- the break.pas cause

*ewa dar- aka- shka- $\mathrm{n}$ t- an you pl wood- the break.pas cause 2s- pl "You broke the wood"

*awan dar- aka- shka-
they wood- the break.pas cause

Subject agreement in Sorani is considered a challenge to the syntactic theories as there is no good explanation available to understand this phenomenon. In my next section I will explore the nature of this agreement marker as this would be the key to explaining the agreement phenomenon in Sorani.

\section{4-Clitics or affixes}

A close examination of the nature of the agreement marker in Sorani shows that it is not obvious whether it is a suffix or a clitic. In what follows I will discuss the properties of the affixes and clitics in general, and then apply them to the data in Sorani to decide whether the agreement marker is an affix or a clitic.

Clitics are, by definition, "neither clearly independent words nor clearly affixes" (Zwicky 1977:1). A clitic is a type of obligatory bound morpheme which is generally distinguished from affixes in the literature. There are differences in the positions in which the clitic can occur in different languages. It has been argued in the literature that clitics in some languages can occur in different positions as is found in Polish and in this case it would have a kind of free movement Haspelmath (2002), as the following examples show:

(29) Tak bardzo-go choia-tby-m spotkac w pholend So much him want-hyp-1sg meet in poland

"I would so much like to meet him in Poland"

(30) tak bardzo chcia-tby-m-go spotkac w pholand

So much want-hyp-1sg him meet in Poland

"I would so much like to meet him in Poland" 


\section{(31) Tak bardzo chia-tby-m spotkac-go w Pholand So much want-hyp-1sg meet him in Ploand "I would so much like to meet him in Poland"}

( Haspelmath, M.2002,Pp 152)

In Polish, the third person object pronoun jego, 'him', of which there exists a clitic 'go.' This cliticized form of the object pronoun can occur at different positions of the sentence. The cliticized form of the object pronoun appears on the adverb in (29), and on the verb chcia 'want' in sentence (30), and in (31) it appears on the verb spotkac 'meet.'

Clitics can occur in the second position in the sentence, attached to the first element in the sentence as in Serbian languages as shown in the following examples:

(32) Covek-je voleo karina

Humanhas loved animals

"The human has animal"

(33) Voleo-je covek karina

Loved-has human animal

"The human has animal"

(34) Karina-je covek voleo

Animal-has human loved

"The human has animal"

( Haspelmath, M.2002,Pp 152)

Haspelmath(2002) states that there are languages in which the clitics have freedom of movement as in Polish, and there are languages in which the clitic appears in the second position, in other words it occurs directly after the first element of the sentence as in the Cerbian language.

However, the occurrence of the clitic in what is known as 'second position clitic' in some languages as the Serbian/Croation languages shows that the clitic cannot move to any position but, there is a restricted freedom of movement for the clitic in some languages such that the clitic should be attached to the first element of the sentence, i.e. the clitic will always occur at the secondposition. For example, the Serbian/Croation, the auxiliary verb je is such a clitic. ${ }^{1}$ This clitic has to occur always at the Second position in the sentence and what occurs at the first position is not relevant to the occurrence of this clitic in this language as it is shown in (32), (33), and (34) (Haspelmath, 2002).

Haspelmath (2002) states that the movement of clitic is possible in languages that allow the movement of the full form of the element to which the clitic is attached. Thus, in English the clitics forms '-ve, - 'll, -,- 's' cannot move out of their hosts as in (35) and (36)

(35) They've done it (They have done it)

(36) *They done've it *(They done have it)

But the corresponding full form of these clitics can move as in (37):

(37)

a. They've done it.

b. Have they done it?

On the other hand, affixes are morphemes that are attached to a word stem to form a new word, they are bound to their hosts, together with their hosts; they form a single phonological word as the word 'boys' in which the affix ' $s$ ' that indicates not only a single 'boy,' but a group of boys is attached to the noun 'boy' and together they form one word. Affixes can be derivational, like English -ness as in (38), or inflectional, like English plural -s and past tense -ed. as in (39).

(38) slow + -ness $=$ slowness 


\section{(39) open + ed= opened}

The affixes are bound morphemes by definition as examples (38) and (39) show and they have no meaning in Isolation; however; prefixes have more independency as they have meaning even alone, for example, the prefix anti- means 'against': (40):

(40) anti-war

Affixation is, thus, the linguistic process speakers use to form different words by adding morphemes (affixes) at the beginning of the word which is called prefixation, in the middle which is called infixation, ${ }^{1}$ or the end which is called suffixation. Affixes have a restricted distribution in that they can only occur with a subset of words in a language, generally a single lexical class. For example, in English the affix -ed can occur only with verbs to indicate past tense, and it cannot occur with nouns or adjectives. Affixes cannot occur independently in the absence of an appropriate host. In addition there are often arbitrary paradigmatic gaps and morphological and semantic idiosyncrasies found with affixes for example the $-s$ that marks plurality in English fails without a clear reason to combine with some nouns such as 'man' or 'ox.' (Zwicky and Pullum 1983)

It is difficult to distinguish between clitics and affixes as both of them are bound morphemes, Zwicky 1971, Pullum 1983, Zwicky 1977, and Klavans 1985 distinguished between clitics and affixes properties and state them as follows:

1- Affixes can show a high degree of selection with respect to their hosts while clitics show a low degree of selection to their hosts (Fattah 1997). This means that the affixes obey a restriction of the word class they attached to while this restriction is relatively less discriminating in the case of clitics. For example, -est attaches to adjectives, -ing attaches to verbs, plural marker attaches to nouns and so on as in (41). It appears that there is no such boundary regarding the clitics as in (42):
a. $\quad$ He is the smartest in the class
b. $\quad$ He is working hard for this exam
c. There are many smart boys in the class

a. The house I was born in' $\mathrm{s}$ (in is) been destroyed

b. $\quad$ Any person who is corrupt 's (is)

c. The ring she sent's lovely.

2- A clitic is a reduced form of a word that has a full form elsewhere in the language. The forms - 's,-' $d$, - 've and -' $l l$ as the reduced form of 'has, had, have and will are respectively the instances of clitics in English. While in English the affixes $-s,-$ ness do not have full forms.

3 - The contribution of a clitic to a sentence meaning is identical to the contribution of the full forms, although they do not necessarily occur in the same syntactic position as their corresponding full forms, as the following examples indicate:

(43) She'll travel tomorrow, is equal to

(44) She will travel tomorrow

' A clear example of infixation would in Arabic: the infix - $t$ - can be inserted in the verb jahida 'he strove' and it changes the verb into ijtahada ' he works hard.' 
This is not true regarding affixes in many cases. For example, the degree marker '-est' when attached to an adjective gives us a paradigm like, 'great-greater- greatest' or 'good-better-best' as in:

(45) He is the best teacher in my school

Here, best has the meaning 'surpassing all other teachers in the qualities of teaching' however, it is not the same case in (John was the best man at their wedding) the word best does not mean the same thing as being described above (Das 2010).

4-Affixes are attached to lexical categories such as a noun, adjective or verb. For example an affix -ed is attached to the most of the verbs in English to mark past tense of the action. Clitics in contrast are attached to the phrasal categories, although they will always be phonologically attached to a single word in that phrase. For example,
Affixes
(46) I have worke for this
(47) I walk-ed home last night

\section{Clitics}
(48) He is leading a dog's life.
(49) The king of England's daughter is in China

The properties of clitics and affixes discussed above show clearly their different functions and positions in the structure of the sentence. In the next section I will test the properties of the agreement marker in Sorani against the clitic properties to find out if the agreement marker in Sorani is a clitic or an affix.

\section{5-Clitics in Sorani}

There are a number of forms in Sorani which have all the properties of clitics. These include:

(a) Subject agreement: The verb agrees with subject. The agreement marker on the verb always agrees with the subject in person and number.

(50) min rowisht- im bo qutabxana

I go.pas- $1 \mathrm{~s}$ to school

'I went to school'

(b) The plural marker and its allomorphs,-an, -yan, and -yak. For example, the plural marker morpheme can appear as full form as in:

(51) xward- i- yan

"They ate it"

$$
\text { eat.pas- 3s- } \mathrm{pl}
$$

Or it can appear as a clitic as in:

(52) Kur-ak- an nan- da- xon

boy- the- pl bread asp- eat.pres

"The boys are eating"

(4) The definitive marker, and its allomorphs: $-a k a,-a,-a k,-k$, etc. For example the definite marker appears in its full form as in:

(53) Kur- aka zerak- a

boy -the clever- is

"The is clever" 
Or it can appear as a clitic as in:

(54) Kur- a zerak- aka bra- m- a boy- the clever -the brother -mine-is

"The clever boy is my brother"

These can be distinguished from other affixes as they have the following properties:

(1) Clitics can be attached to nouns, verbs, or adjectives. In other words, the hosts of the clitics are not limited to a certain word category. The pronominal clitics in Sorani, unlike any affix, can attach to words of virtually any category, be it, a noun, a quantifier, a negative marker, a verb, etc. Illustrative are the following examples:

(55)

a. nama- ka-m nus- i

letter- the-ls write.pas

"I wrote the letter"

b. na-m- kir-i

n- 1s-buy.pas

"I did not buy it"

c. da- xwen- im

d. zor- $\mathrm{m}$ gu-t

asp- study_pres. $1 \mathrm{~s}^{1}$

"I study"

alot- Is say.pas

"I said a lot"

The affixes, by contrast, are quite specific in the selection of their host as seen in table (1). The indefinite marker invariably attaches to nouns (e.g. kur-r-ek 'a boy'), and it cannot be attached to verbs (*roishtnek 'a walk') or to an adjective ( *jwanek 'a beautiful'). The negative markers is attached to verbs, (e.g. na-xom 'I don't eat'), but not to nouns ( *na-kchek ' not girl').The comparative and superlative indexes to adjectives and to a lesser degree to adverbs tallest, (e.g. zutir jwa n-tir 'more beautiful').

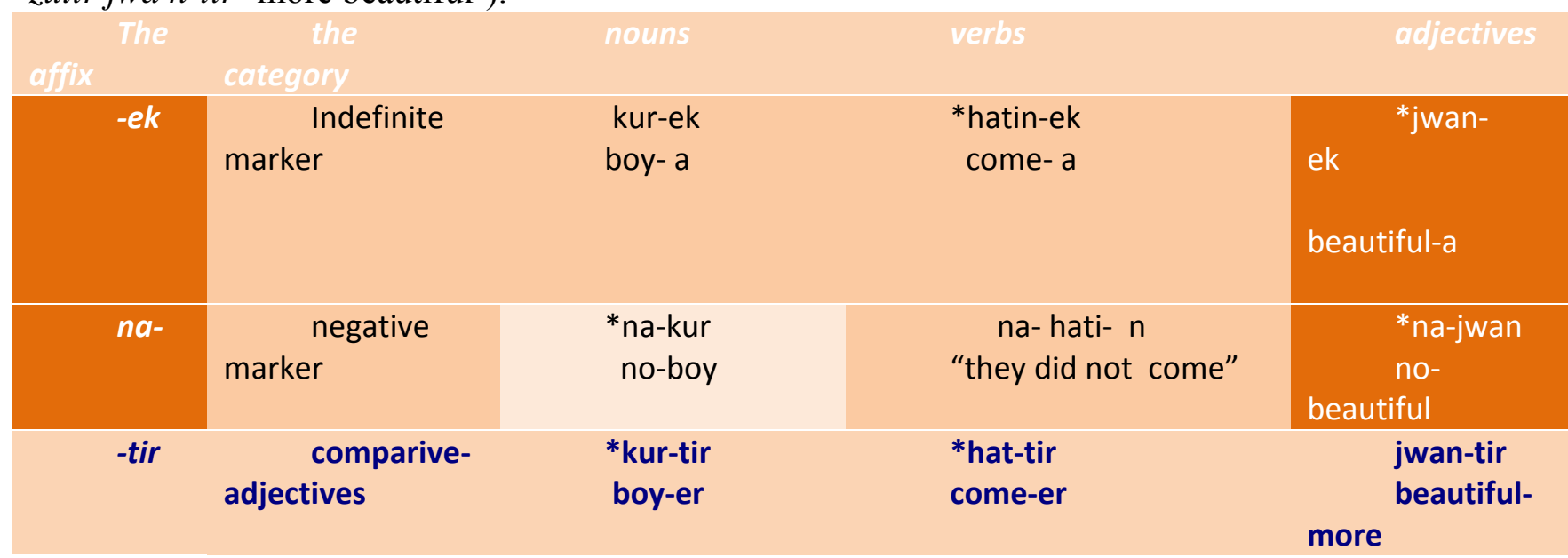

Table(1): specific selection of affixes 
(2) Some clitics, in contrast with affixes have variant full forms as well as clitic forms, for example in English one can use 'have' in its full form as in (we have done it), or in its reduced form as in (we've done it). The same is true in Sorani Kurdish as in (e.g. min,- 'I', to,- $t$ it 'you', aw, $i$ ' he, she, it', awan,-yan 'they', ema, -man 'we', ewa, -ta:n 'you all). But, affixes can only be found in their reduced forms, for example the affix -ek 'a' can only appear in its reduced form and it is attached to nouns because when it appears in its full form yak 'one' it will not be considered as an affix anymore, but rather as an independent word (Fattah, 1997). The contribution of clitics to a sentence meaning is identical to the contribution of their full forms, although they do not necessarily occur in the same syntactic position as their corresponding full forms. (Zwicky1985), since they do not share the distribution of their full forms, as the following examples indicate:

(56)

a.

$$
\begin{gathered}
\text { min awan-im } \mathrm{d}-\mathrm{i} \\
\mathrm{I} \text { they- } 1 \mathrm{~s} \text { see.pas }
\end{gathered}
$$

"I saw them"

b. di-m- in

see-1s-Ip-o

"I saw them"

c. aw min- i xwar-d

he I- 3s eat. pas

"He pestered me"

d. xwar-d- im- i

eat. pas o- $3 \mathrm{~s}$

"He pestered me"

(3) Clitics always appear on the edge or the boundaries of the words; they cannot be infixed within words. In other words they have an edge effect as shown in (57) and (58) in English and Sorani respectively:

(57) a. do+es+n't=doesn't

b. $\quad *$ don'tes

$$
\begin{aligned}
& \text { a. kur-ek-im di } \\
& \text { boy a } 1 \mathrm{~s} \text { see.pas } \\
& \text { "I saw a boy" }
\end{aligned}
$$

b. $\quad$ *kur- im- ek di

boy- 1s- a see.pas

"I saw a boy"

The clitics are external not only to stems as in (57) in English and (58) in Sorani, but they can be external to the whole phrase as in (59), and (60) in English and Sorani respectively:
a. The man in the room's hat
b. * The man's in the room hat 
(60)

a.

$$
\begin{aligned}
& \text { kura-ak-a-nim d- i } \\
& \text { boy -the-pI-Is see_pas } \\
& \text { "I saw the boys" }
\end{aligned}
$$

b. $\quad$ *kur- im -ak-an di boy-1s-the-pl see.pas

"I saw the boys"

While the affixes can be easily infixed with words as (61) shows or precede the words and in this case they are called prefixes as in (62).

(61) kur- ek-i aza- $m$ bene

boy- a -iza brave- $1 \mathrm{~s}$ see.pas

"I saw a brave boy"

(62) kur- aka kurse- ka- i hal- bre

boy- the chair- the- $3 \mathrm{~s}$ up- cut.pas

"The boy lifted the chair"

(4) Semantic idiosyncrasy is more a characteristic of affixed words than of clitic groups, i.e. the semantic contribution made by a clitic to a sentence is equivalent to that of a corresponding full word. For instance, clitic groups containing $-m$ will always be identical in meaning with constructions containing the full form $\mathrm{min}$. By contrast, inflection sometimes displays a shift in meaning. For example the affix -an, the plural marker, often conveys a temporal meaning as in salan 'in the past', jaran 'formerly, and sawan 'by night.'

(63) Min roisht- im bo qutabxana

I go.pas- 1s to school

"I went to school"

(64) Roisht- im bo qutabxana go.pas- $1 \mathrm{~s}$ to school

"I went to school"

In (63) the pronoun $\min$ ' $\mathrm{I}$ ' is dropped from the sentence, but the sentence is still grammatical in (64) as the clitic $-m$ has the same semantic contribution in the sentence, but this cannot be true regarding the semantic contribution of the affixes as shown in (65) and (66):

(65) Kur- ak- an nan- da- xon boy- the- pl bread asp- eat.pres

"The boys are eating"

(66) Sal- an xyan asan- buu year- pl life easy - was

"Life was simple in the past"

In (65) the affix -an changes the noun kur 'boy' from single into plural kurakan 'boys, but in (66) the affix - an has a different semantic contribution in the sentence, it changes the word sal 'year' into salan 'in the past,' in other words, it change the semantic of the word (Fattah,1997). 
As it is shown clearly that all the properties of the clitics can be applied on the agreement marker in Sorani and this means that the verb agrees with the subject by means of cliticization.

The big question that should be asked now is where the clitic is generated, how it joins the verb or the object when the sentence includes past transitive verb?

In the next section I will examine the structure of the verb and the verb phrase as this will guide me to answer the above questions.

\section{6-The structure of the verb phrase in Sorani Kurdish}

The verb in Sorani Kurdish is a complex element that has an internal and external structure. The verb stem in Sorani incorporates tense which represents the minimal content of the verb as in (Fattah, 1997):

(67) shka- nd- im

break.pas- cause- $1 \mathrm{~s}$

"I broke it"

(68) shka- nd- i

break.pas-cause-2s

"He broke it"

The verb stem can be preceded by three heads that are represented by bound morphemes attached to the verb, the three heads are the following and they come in the order shown below:

1-pre-verbs as ra, ro, and da:

(69) ra- $m$ kird

pre- 1s- make.pas

"I ran"

2- Negation particle na:

(70) ra- m- na- kird

pre- 1s- not- make.pas

"I did not run"

3- Aspect marker as $d a$ and $b i$ :

$$
\begin{array}{cc}
\text { ra- } m-\text { na- da- } & \text { kird } \\
\text { pre- } 1 \text { s- not- aspc- } & \text { make.pas }
\end{array}
$$

"I was not running"

Any change in the order of those elements would result in an ungrammatical sentence:

$$
\text { *na- ra- m- da- kird }
$$

not- pre-1s- aspec- make.pas

"I was not running"

The verb stem in Sorani can also be expanded to right by suffixation as in:

(73) darg- aka- $m$ daxit- awa

door- the -1 s close.pas- affix (again)

"I closed the door again" 
Fattah (1997) mentions seven different suffixes that can be attached to the right of the verb stem in Sorani, they have certain order and they never come all together in one series:

1-Applicative or causative as:

(74) shka-nd-im

break.pas- cause-1s

"I broke it"

2-participle as in:

(75) da- m- xist-

ua

pre- 1 s- close.pre- p.p

"I have not closed it"

3-passive as in:

(76) chesht- aka xu- ra

food- the eat.pas-was

"The food was eaten"

4- Conditional marker as in:

(77) broish- tet- aya gaesht- boit esta go.pas- 2 s- if reach- were by now

"If you had went, you had been reached by now"

5-Agreement marker as in:

(78) peyaw-aka- an roisht- in man- the-pl go.pas- 3s.pl

"The men left"

6- Additive marker as in:

(79) xward- i- shi

eat.pas-3s- too

"He ate it too"

7-Iterative suffix as in:

(80) garan- im- awa

look.pas- 1 s- again

"I returned it back"

All the elements that can proceed and follow the verb, especially the ones that create dependencies between the different parts of the sentences, should be assigned functional heads. In other words they have to be represented as heads that projecting phrases. Therefore, the morphosyntactic formative that is equivalent to a functional category is syntactically the head of the maximal projection. Accordingly, the functional heads in Sorani would include: agreement, tense, passive and negation markers. (Please see Speas 1990, Ouhalla 1991, Hendrick 1991). 
To give the reader a clear picture about the structure of Sorani, the elements of the verb phrase in Sorani have been shown above, and the sentences appear in the word order SubjectObject-Verb. The verb is marked for tense and aspect and usually agrees with the subject in person and number.

$$
\begin{aligned}
& \text { Kur- aka dar- aka da- } \begin{array}{c}
\text { shke- } \\
\text { n- }
\end{array} \\
& \text { boy- the wood- the asp break.pres- cause- } \\
& \text { 'The boy breaks the wood' }
\end{aligned}
$$

I will propose a simple structure to show how the agreement marker is cliticized to the intransitive verb in the past and the present tense, as well as to the transitive verb in the present. Second I will deal with transitive verb in the past where the agreement marker appears on the object instead of the verb.

a. Agreement in a present transitive verb:

I will start with a simple sentence as in (82):

kur- aka- $\mathrm{n}$ sew $\begin{gathered}\text { da- } \\ \text { xwo- }\end{gathered}$ n.
boys- the- pl apple asp
'The boys eat apples'

In the above sentence the verb xwo 'eat' has two elements in its theta grid. One of these is associated with a theme theta role and selectional $\mathrm{N}$ - features. The other is associated with an agent theta role. In (82) kurakan 'the boys' is assigned the agent theta role, and sew 'apples' is assigned the theme role. The verb xwo 'eat' merges with sew 'apples' and this satisfies the uninterpretable feature of $x w o$ 'eat' forming the VP. As shown above the aspect marker $d a$ - is attached to the verb, indicating that a Functional categorical head ASP is projected. V raises up to identify aspect. The verb daxo 'eating' still has an uninterruptable agreement feature, therefore, an AgrP will be projected to satisfy the unvalued agreement feature on the verb $d a-x w o$ 'eat.' The verb raises to check the uninterpretable agreement feature in Agr. The agreement marker cliticizes to the verb, as the clitic has to be attached to something because it cannot stand alone. The $\mathrm{V}$ raises and merges with $\mathrm{T}$ to identify tense which give it the structure in (1):

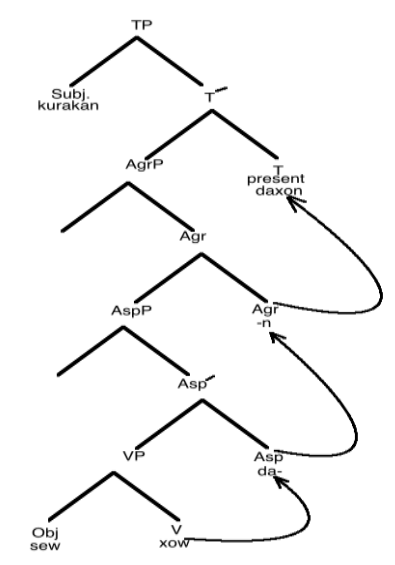

\section{Structure (1) agreement in the present tense}

B-Transitive verbs in the past tense:

In the past transitive verb, the agreement marker appears on the object as in (83):

(83) kur- aka- $\mathrm{n}$ sew- i- an xward boy the- $\mathrm{pl}$ apple- $3 \mathrm{~s}-\mathrm{pl}$ eat.pas

'The boys ate the apple' 
The transitive verb in the past tense merges with the object sew 'apples' and this satisfies the uninterpretable feature of $x w o$ 'ate' forming the VP. As morphologically the aspect phrase is empty, the verb does not raise to aspect node, but the object raises to the spec of the aspect phrase to identify aspect. As shown in (2) the agreement marker is in the spec of the aspect phrase, and it has to be cliticized to an element, the nearest element is the object. Therefore; the agreement marker cliticizes to the object resulting in sew-ian 'apple+agreement;' the verb raises high to the right to merge with tense and get tense. This gives the sentence structure as in (2):

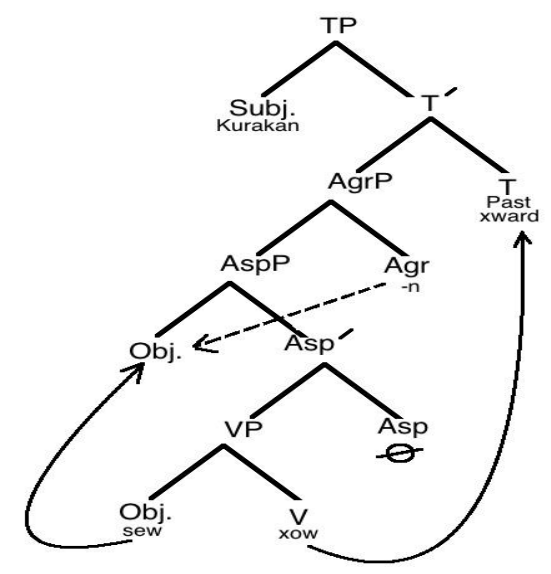

\section{Structure (2) agreement in the past tense}

Subject -verb agreement in Sorani is realized as a clitic that appears on the verb in the transitive present tense verbs and the intransitive past tense verbs. The agreement marker cliticizes to the verb as it cannot stand alone; therefore the agreement clitic appears on the verb. While the agreement marker appears on the object in the transitive present tense verb as the verb does not raise, but the object raises to identify aspect. When the object raises, it will be the nearest element to which the agreement marker can cliticize, therefore, the agreement marker appears` on the object in the present transitive verb tense.

\section{References}

1. Abdulla, J. J. (1967). Kurdish basic course: dialect of Sulaimania, Iraq. Ann Arbor: University of Michigan Press.

2. Bodnarchuk, Kari J. (2000). Kurdistan, Region under Siege. Minneapolis: Learner Publications Company.

3. Das, P.K. (In- progress) (2010) "Clitic: an introduction." Department of Linguistics, University of Delhi. Available at http: //people.du.ac.in/ pkdas/.

4. Fattah, M. M. (1997). A Generative Grammar of Kurdish. Unpublished Ph.D Dissertation, University of Amsterdam

5. Haspelmath, M. (2002) Understanding Morphology. United States: Oxford University Press.

6. Hendrick, R. (1991) The morphosyntax of aspect. Lingua 85, 171-210.

7. Klavans, Judith L 1985. "The Independence of Syntax and Phonology in cliticization." Language 61:95-120.

8. Ouhalla, J.(1991) "Functional Categories and Parametric Variation" London: Rutledge

9. Speas, M.J. (1990) "Phrase structure in natural languages. Dordrecht: Kluwer.

10. Zwicky, Arnold M. 1977. "On clitics.” Bloomington, IN: Indiana University Linguistics Club.

11. Zwicky, Arnold M., and Geoffrey K. Pullum. 1983. "Cliticization vs. inflection: English N'T." Language 59 (3):50213.

12. . 1985. "Clitics and particles." Language 61 (2):283-305. 